\title{
Predation Capability of Black Kite (Milvus migrans parasitus) on Locust as a Biological Control Option in Madagascar
}

\author{
Mahitandrainy Jules Andriatsirevombola ${ }^{1}$, Jiwen Ge ${ }^{1 *}$, Raholijaona ${ }^{2}$ \\ ${ }^{1}$ School of Environmental Science, China University of Geosciences, Wuhan, China \\ ${ }^{2}$ Free Consultant in Ecology, Antananarivo, Madagascar \\ Email: "gejiwen2002@aliyun.com
}

Received 5 March 2016; accepted 24 April 2016; published 27 April 2016

Copyright (C) 2016 by authors and Scientific Research Publishing Inc.

This work is licensed under the Creative Commons Attribution International License (CC BY). http://creativecommons.org/licenses/by/4.0/

(c) (i) Open Access

\begin{abstract}
In Madagascar, the South and Southwest regions have for decades had locust outbreaks that have devastated crop fields. The locust species dominant in this area are the red locust (Nomadacris septemfasciata) and the Migratory Locust (Locusta migratoria capito). This paper aimed at determining the predation values from the Black Kite (Milvus migrans parasitus), a natural enemy for locusts, as a biological measure for locust outbreak control. Two types of experiments were done that included observed predation and experimental predation. It was observed, in the observed predation, that a higher number of locusts were found in the bird's stomach during the afternoon session (mean $=66$ ) than during the morning session (mean $=21$ ). The high peak observed during the afternoon session was also associated with the feeding of larvae of the migratory locust. The experimental predation results showed that almost 100 percent of the larval and 97 percent of the fledglings were fed on. The experimental predation results also showed that there was no preference for larvae or fledglings in the cage and that the bird fed on the different combinations equally. This study showed that the Black Kite birds can effectively control locust population in an outbreak when they are easy to predate on. However, there is a need to assess the population of birds in locust infested areas to determine if the bird population is enough to predate on a locust outbreak.
\end{abstract}

\section{Keywords}

Integrated Pest Management, Milvus migrans parasitus, Locust, Madagascar, Avian Insectivory

\footnotetext{
${ }^{*}$ Corresponding author.

How to cite this paper: Andriatsirevombola, M.J., Ge, J.W. and Raholijaona (2016) Predation Capability of Black Kite (Milvus migrans parasitus) on Locust as a Biological Control Option in Madagascar. Open Journal of Ecology, 6, $254-263$. 


\section{Introduction}

Agriculture has been a very important sector in the economic development of countries for a very long time. The importance of agriculture lies in its ability to be a source of employment, raw material for industrial production, income to governments and most importantly as a source of food (Tiffen, 2003) [1]. In developing countries, the role of agriculture to poor families which spend less than a dollar a day is the only source of income and food; unlike in developed countries that have a variety of income generating options. Over 70 percent of poor families in developing countries are located in rural parts that have adequate land for crop production and pasture land for feeding livestock, but also spend their valuable working time in various agricultural activities (Hertel and Rosch, 2010) [2]. Despite the importance of agriculture to the rural poor population in developing countries, there have been various concerns in the ability of agriculture being reliable to the poor families to offer the required income and even food for the families. The poor families have consistently found agriculture to be unreliable because of low crop yields that are experienced every growing season. A lot of the farmers in developing countries often do not produce enough to feed their own families. The low crop yields in Madagascar, a poor African country, have been attributed to many factors that include loss of soil fertility, poor farming practices, climate change and use of unimproved crop varieties. However in South and Southwest regions of Madagascar, which are heavily infested by locusts, the most important factor leading to low yields is insects (Lecoq et al., 2011) [3].

In Madagascar, the South and Southwest regions have for decades had locust outbreaks that have devastated crop fields (Lecoq et al., 2011) [3]. The locust species dominant in this area are the red locust (Nomadacris septemfasciata) and the Migratory Locust (Locusta migratoria capito), both of which have geographically restricted outbreaks (African Development Bank, 2001 [4]; Magor et al., 2008 [5]). The geographical restriction for the locusts is associated with the perfect environmental conditions in the region that allow them to go through the various stages of reproduction and also successfully survive. The solitarious and gregarious phases are the two main phases of locust population that represent the low population stage and the swarm population stage respectively (Sánchez-Zapata et al., 2007) [6]. However, the gregarious phase is associated with crop destruction, because of the increased locust population that causes significant harm to crops and other types of vegetation. The behavior of locusts has led to them being categorized as pests because they are organisms that interfere with the goals and activities of humans (Lomer et al., 2001) [7]. In the context of agricultural production, a pest can be defined as an organism which negatively influences the production of food and fiber (Shelton, AM, BadenesPerez, 2006) [8].

Pest control has exited ever since humans started growing crops and rearing livestock as a source of food. In agricultural production, there is always a competition between humans and pests for limited resources required for growth of crops and survival of pests. In view of this, there has always been the need in agriculture production to control and mitigate the negative effects of pests through the use of various pest control practices. In Madagascar the use of chemicals as a control practice has been preferred and overused for a long period of time, but it is both expensive and leads to environmental pollution. Despite the focus on chemical control of locusts in Madagascar, there are three other options and include biological controls, cultural controls and physical controls. Biological controls generally include the use of predators and disease causing organisms for the control of pests (Kar et al., 2012) [9]. A combination of these four categories of pest control is referred to as integrated pest management (IPM). The IPM approach is considered a better option because individual pest control initiatives do not have an effective outcome when compared to an integrated approach.

Many studies have been conducted to assess the beneficial direct interactions that exist between birds and plants (Meehan et al., 2005) [10]. Birds are known to play important roles as pollinators (Meffe, 1998) [11], seed dispersers (Stiles, 2000) [12], seed predators (Castro et al., 1999 [13], Howe and Brown, 1999 [14]), and herbivores (Noordhuis et al., 2002) [15]. These direct interactions have been shown to affect plant population dynamics and community structure, as well as the evolution and expression of plant life histories and morphologies (Meehan et al., 2005) [10]. Many bird species feed on locusts, but their ability to keep the locust population in check so as to avoid economic damage is not clearly known (Kirk et al., 1996) [16]. M. m. parasitus is widely distributed in sub-Saharan Africa, Comoros, and Madagascar and has strong intra-continental movements (Cramp \& Simmons, 1980 [17]; Fergusson-lees \& Christie, 2001 [18]). It is a migratory bird that flies to Madagascar every year at around the time when the weather and food competition is suitable for its survival and reproduction. This migratory behavior brings the bird species in large numbers making them a menace to the locust pop- 
ulations. Associated to the migratory behavior the bird occupies the study area (South and Southwest of Madagascar) in the period ranging from November to March, which is a time that coincides with high locust swarm development and propagation period. In this study, we considered the Black Kite (Milvus migrans parasitus) bird species in the area as a natural enemy for locusts; hence act as a biological preventive control method. However, questions existed on the locust feeding capability of the Black Kite (Milvus migrans parasitus) bird species to be considered as an effective biological preventive option that can form part of an IPM program. This paper aimed at determining the predation values from the Black Kite (Milvus migrans parasitus) bird species as a measure of effectiveness for locust outbreak preventive control. Furthermore, the study determined the predation values during both solitarious and gregarious phases.

\section{Materials and Methods}

\subsection{Study Area}

Madagascar is an African Island country that is located in the Indian Ocean and has a wide variety of biodiversity. This study was focused on the South and Southwest regions of Madagascar, which have a known record of locust outbreak problems. Just like the general biodiversity range of Madagascar, the South and Southwest regions have equally diverse vegetation that has mosaic vegetation units, which include Savannas, steppes, forest galleries, wastelands, and bushy areas. The study area is divided into three ecological zones based on the amount of rainfall received per year. Based on the annual rainfall amounts, the area is divided into three ecological units that support growth and development of locust swarms. The first ecological zone receives annual rainfall of 750 - $800 \mathrm{~mm}$, the second zone records annual rainfall amount of $400-500 \mathrm{~mm}$, and the third zone with the least average amount of rainfall receives $350-400 \mathrm{~mm}$. These ecological zones are also associated with locust's solitarious and gregarious phases; with the highest rainfall receiving zone being the multiplication area and the other zones being multiplication transitional area and densing area respectively.

Two sampling stations were selected on the three ecological units associated with locust swarm development. The two stations were Bekily and Isoanala. Isoanala station located $23^{\circ} 50^{\prime}$ South and $45^{\circ} 43^{\prime}$ East, occupies an area of $3.75 \mathrm{~km}^{2}$. The Isoanala station was an open environment that consisted of anthropic mosaic polyculture fields of various plant species such as Acacia Tote has sp., Heath has Indigofera sp., Heteropogon contortus (Poaceae), Cynodon dactylon (Poaceae) Hyhaena Shatan (Arecaceae) and Eucalyptus sp. This station had several water stations and was favorable area for locust to propagate. The other station of Bekily are found between coordinates $23^{\circ} 21^{\prime}$ to $24^{\circ} 05^{\prime} 14^{\prime \prime}$ South and $44^{\circ} 8^{\prime} 59^{\prime \prime}$ and $44^{\circ} 12^{\prime} 05^{\prime \prime}$ East. The station had have fertile soils that favor pasture growth and transhumance for farmers in surrounding areas. From the vegetation point of view, the Bekily had a dry bush land dominated by Heteropogon contortus grass species. The Bekily station was classified as the multiplication and gregarizing area.

\subsection{Bird Sampling and Data Collection}

There are over 40 bird species in the study area of which 11 are known locust predators. One of these bird species, the Black Kite (Milvus migrans parasitus) was selected because it is acknowledged as the main migratory insectivores. The Black Kite bird is a migratory bird and its largest population attendance in the months of November/December to June/July every year coincides with the locust outbreak periods. Furthermore the Black Kite bird is dominant in South and Southwest of Madagascar, and feeds on locusts larval and fledglings.

Observed predation (OP), 30 individuals' Black Kite birds (Milvus migrans parasitus) was sacrificed during this experimentation field works, the OP was done by examining stomach contents of hunted wild birds. It was based on determining the number of locust fed but also the development stage of the locust (whether larvae or adult). The stomach contents of birds were examined at different times of the day, and from different locations within the study under various locust events (spot, hopper band or swarm) either in remission or gregarious periods. During stomach content examination, the presence of non-digestible components such as head, abdomen, femur, and wings were used to identify the captured locusts. This method also provided information on the period of day when the bird's predation of locust was highest.

The experimental predation (EP) was done at Isoanala station and involved capturing breeds that were placed in semi-natural cages. The cages were made of wire mesh installed directly on the ground, and were $2 \mathrm{~m} \times 1 \mathrm{~m} \times$ 1.5 in size. In the cage, individual of Black Kite birds (Milvus migrans parasitus) was fed locusts of different 
developmental stages (larvae and winged); the locusts were fed in three different combinations of only larvae, only adult locusts, and a combination of hoppers and adults. The locusts fed to the bird were counted before being placed in the cages and the remainders were also counted to know the number of locusts not fed on. The bird in the cage was fed every morning and the remainders were removed in the evening of each day. This captivefeeding method was used to determine predation of an individual bird species on locusts of different development stages.

\subsection{Data Analysis}

Studies of bird predation on locust were conducted from October 2012 to May 2013. Two types of experiments were done that included 1) experimental predation to estimate potential predation rate of birds on locusts; and 2) examination of captured bird stomach content. The results from these experiments were calculated by using descriptive statistics that included frequency, mean and standard deviation. The t-test was used to test the significance of the differences between the two group means, and the level of significance was set at 0.05 .

\section{Results and Discussion}

\subsection{Observed Predation}

Stomach content data for the bird was collected by hunting the birds during two sessions of morning and afternoon (Table 1). The two sessions were separated to determine the time of day when the birds fed more.

Table 1. Black kite (Milvus migrans parasitus) bird stomach examination results.

\begin{tabular}{|c|c|c|c|c|}
\hline Shooting times & Bird identity & Amount of locusts captured & Locust type & Vegetation \\
\hline $10: 00$ to $10: 30 \mathrm{hrs}$ & $1 \mathrm{M}$ & 22 & Winged Nomadacris & Savannah \\
\hline $10: 00$ to $10: 30$ hrs & $2 \mathrm{M}$ & 19 & Winged Nomadacris & Savannah \\
\hline $10: 00$ to $10: 30 \mathrm{hrs}$ & $3 \mathrm{M}$ & 11 & Winged Nomadacris & Savannah \\
\hline $10: 00$ to $10: 30$ hrs & $4 \mathrm{M}$ & 13 & Winged Nomadacris & Savannah \\
\hline $10: 35$ to $11: 00$ hrs & $5 \mathrm{M}$ & 15 & Winged Nomadacris & Savannah \\
\hline $10: 35$ to $11: 00 \mathrm{hrs}$ & $6 \mathrm{M}$ & 17 & Winged Nomadacris & Savannah \\
\hline $11: 05$ to $11: 30 \mathrm{hrs}$ & $7 \mathrm{M}$ & 10 & Nomadacris larvae & Wasteland \\
\hline $11: 05$ to $11: 30 \mathrm{hrs}$ & $8 \mathrm{M}$ & 26 & Winged Nomadacris & Savannah \\
\hline $11: 35$ to $12: 00 \mathrm{hrs}$ & $9 \mathrm{M}$ & 18 & Nomadacris Larvae & Wasteland \\
\hline $11: 35$ to $12: 00 \mathrm{hrs}$ & $10 \mathrm{M}$ & 47 & Nomadacris Larvae & Wasteland \\
\hline $11: 35$ to $12: 00$ hrs & $11 \mathrm{M}$ & 9 & Winged Nomadacris & Dry forest \\
\hline $11: 35$ to $12: 00$ hrs & $12 \mathrm{M}$ & 11 & Winged Nomadacris & Dry forest \\
\hline $11: 35$ to $12: 00 \mathrm{hrs}$ & $13 \mathrm{M}$ & 29 & Winged Nomadacris & Savannah \\
\hline $11: 35$ to $12: 00 \mathrm{hrs}$ & $14 \mathrm{M}$ & 32 & Winged Nomadacris & Savannah \\
\hline $11: 35$ to $12: 00 \mathrm{hrs}$ & $15 \mathrm{M}$ & 31 & Locusta Larvae & Dry forests \\
\hline $13: 00$ to $14: 00 \mathrm{hrs}$ & $1 \mathrm{~A}$ & 44 & Swarm of Nomadacris & Savannah + Dry forests \\
\hline $13: 00$ to $14: 00 \mathrm{hrs}$ & $2 \mathrm{~A}$ & 27 & larvae of Nomadacris & Wasteland \\
\hline $14: 00$ to $15: 00 \mathrm{hrs}$ & $3 \mathrm{~A}$ & 16 & Swarm of Nomadacris & Wasteland \\
\hline $14: 00$ to $15: 00 \mathrm{hrs}$ & $4 \mathrm{~A}$ & 19 & Swarm of Nomadacris & Wasteland \\
\hline $15: 00$ to $15: 30$ hrs & $5 \mathrm{~A}$ & 23 & Nomadacris Larvae & Savannah \\
\hline $15: 00$ to $15: 30 \mathrm{hrs}$ & $6 \mathrm{~A}$ & 25 & Nomadacris Larvae & Savannah \\
\hline $15: 00$ to $15: 30 \mathrm{hrs}$ & $7 \mathrm{~A}$ & 40 & Big swarm of Nomadacris & Savannah + Dry forests \\
\hline $16: 00$ to $16: 30 \mathrm{hrs}$ & $8 \mathrm{~A}$ & 215 & Locusta Larval & Heteropogon contortus \\
\hline $16: 00$ to $16: 30 \mathrm{hrs}$ & $9 \mathrm{~A}$ & 158 & Locusta Larval & Heteropogon contortus \\
\hline $16: 00$ to $16: 30 \mathrm{hrs}$ & $10 \mathrm{~A}$ & 104 & Locusta Larval & Heteropogon contortus \\
\hline $16: 00$ to $16: 30 \mathrm{hrs}$ & $11 \mathrm{~A}$ & 58 & Locusta Larval & Heteropogon contortus \\
\hline $16: 00$ to $16: 30 \mathrm{hrs}$ & $12 \mathrm{~A}$ & 43 & Locusta Larval & Heteropogon contortus \\
\hline $16: 30$ to $17: 30 \mathrm{hrs}$ & $13 \mathrm{~A}$ & 87 & Nomadacris Larvae & Wasteland \\
\hline $16: 30$ to $17: 30 \mathrm{hrs}$ & $14 \mathrm{~A}$ & 86 & Nomadacris Larvae & Wasteland \\
\hline $16: 30$ to $17: 30 \mathrm{hrs}$ & $15 \mathrm{~A}$ & 42 & Nomadacris Larvae & Savannah + Dry forests \\
\hline
\end{tabular}

M: Morning period; A: Afternoon period 
Furthermore, information on the hunting time period (in hours) was also collected to determine the actual time when the bird was at its feeding best. In this study, locusts referred to red locust (Nomadacris septemfasciata) and the Migratory Locust (Locusta migratoria capito); other types of grasshoppers and insects identified in the stomach were disregarded. The study also collected the locust type and stage of development that was found in the bird's stomach. The development identified were mostly of two groups winged adults and larvae locusts (Table 1). The vegetation identified during this study was composed of five types, which included Savannah, dry forests, Heteropogon contortus, a mixture of Savannah and Dry forests and Wasteland (abandoned land that was previously farm land). A total of 30 birds were hunted and stomach contents assessed, with 15 birds being hunted during each session of the day.

Between the morning and afternoon sessions, it was observed that a higher number of locusts were found in the bird's stomach during the afternoon session (Figure 1). The morning session trend was evenly spread out with small variations, while the afternoon session was constant in the early afternoon but increased in the late afternoon period. The trend specifically increased during sessions from 1600 hours to 1630 hours time period, and afterwards it went down; although not as low as the early afternoon trend (Table 1).

The high peak observed during the afternoon session was also associated with the feeding of Larvae of the Migratory Locust (Locusta migratoria capito) (Table 1). These might have been easy for the birds to capture and feed on as they were less mobile when compared to the winged adults that could fly away hence proving difficult to hunt. This observation may also be true for the birds captured during the morning session that had a lower count of locusts in their stomachs. The morning session had a large number of winged adult locusts captured (Table 1), which could be that the birds found it difficult to capture them; unlike the larvae locusts that were found in the bird's stomach during the late afternoon. Thus the Black Kite bird prefers to hunt on locusts that it can easily catch or that can be captured without wasting much energy.

The vegetation of the study area was also examined to determine if it influenced the bird's ability to capture the locusts (Figure 2). Birds captured feeding on locusts on the Heteropogon contortus grass had the highest average (mean $=116)$ of locust stomach contents. This vegetation also hosted the Larvae of the Migratory Locust, which was found to be the most fed on by the birds (Table 1). This indicated that the Larvae of the Migratory Locust preferred habiting in this vegetation, which is short grass that has a height of about $30 \mathrm{~cm}$. This vegetation was also ideal for the bird to capture the locusts as the grass did not hide the larvae to limit the birds from capturing the prey.

The savannah + dry forests vegetation characterized by a large density of trees per hectare had birds with the highest average (mean $=42$ ) of captured insects in the stomach (Figure 2). This vegetation was characterized by

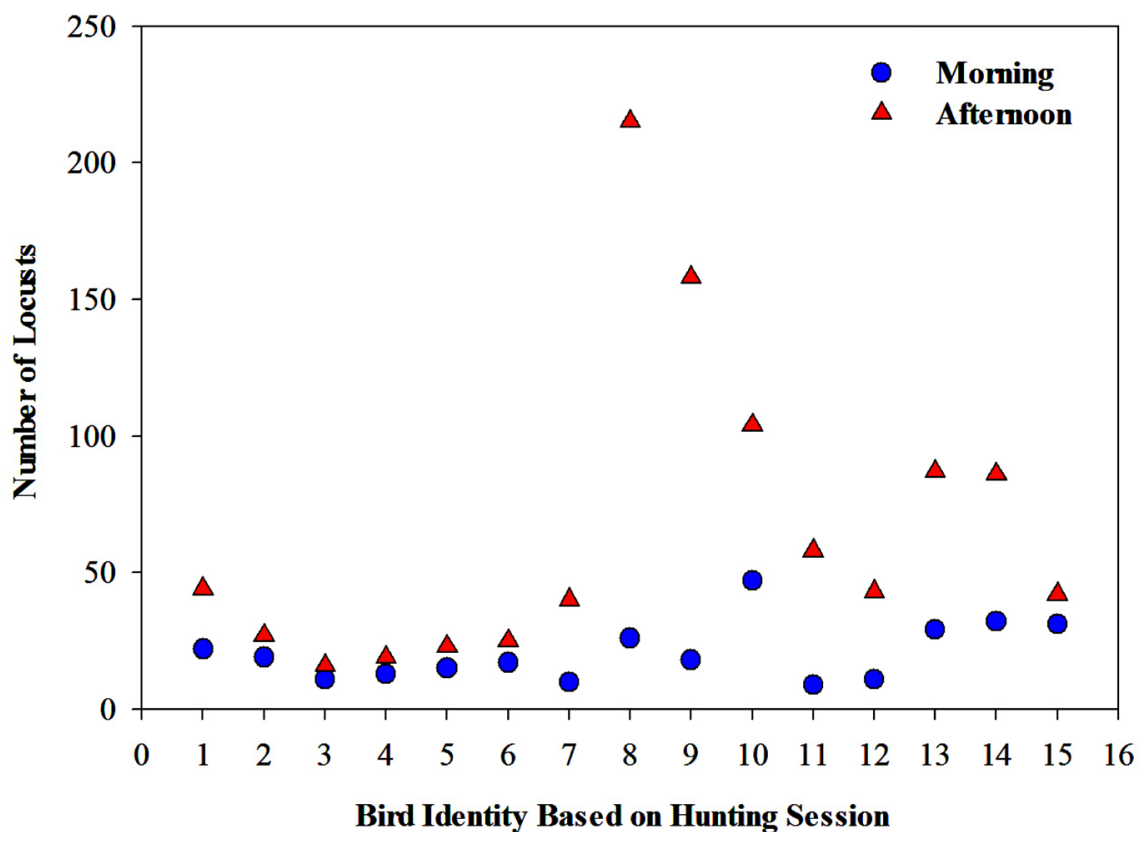

Figure 1. Diagram showing amount of locusts in the bird's stomach during morning and afternoon hunting sessions. 


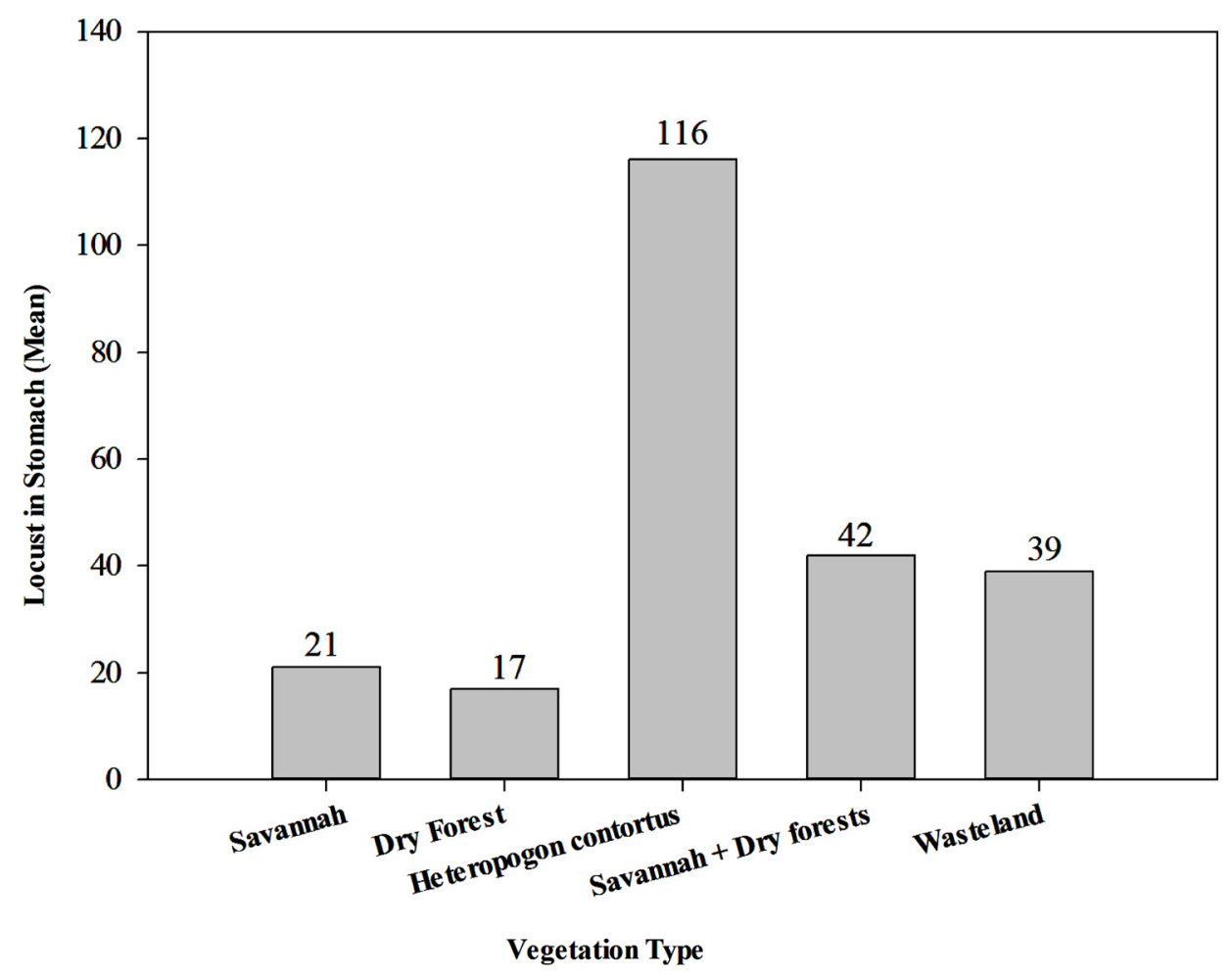

Figure 2. Vegetation type and average of locusts found in birds stomach.

Table 2. Observed predation of the black kite (Milvus migrans parasitus) bird.

\begin{tabular}{ccc}
\hline Calculation & Amount of locusts captured in morning & Amount of locusts captured in afternoon \\
\hline Observed predation & 21 & 66 \\
Std deviation & 11 & 57 \\
Observations & 15 & 15 \\
Degrees of freedom & 15 & \\
t stat & -3.029 & \\
$\mathrm{P}(\mathrm{T} \leq \mathrm{t})$ two-tail & 0.008 & \\
$\mathrm{t}$ critical two-tail & 2.131 & \\
\hline
\end{tabular}

both the adult and larva red locust (Nomadacris septemfasciata). There wasn't much difference between the savannah + dry forest vegetation and the wasteland vegetation that had a mean of 39 locusts found in the bird's stomach. The other vegetation types of big wooded savannah and dry forest followed with means of 21 and 17 locusts found in a bird. This led to the observation that areas that had high vegetative cover, such as with trees, were dominated by adult locusts and birds found it difficult to capture them under such vegetative cover.

The calculated OP for the locusts found in the stomach in total was 43 locusts per bird in a day, while in the morning and afternoon the OP's were 21 and 66 respectively (Table 2). The t-test statistic showed that there was a significant statistical difference $(\mathrm{t}(15)=-3.029, \mathrm{p}=0.008)$ in the total number of locusts eaten in the morning and afternoon, which confirmed that the birds did not have a constant eating pattern. This calculation also confirmed that the birds fed on the locusts mostly in the afternoon than they did in the morning. This locust eating pattern was because of the vegetation type of where the bird had been hunted, which prevented the bird's flight ability in areas with large vegetative cover.

\subsection{Experimental Predation}

The experimental predation (EP) was done to determine the feeding potential of the Black Kite (Milvus migrans parasitus) bird on the locusts. This experiment was important as it took out any natural limiting factors that ex- 
isted in the natural environment, in order to estimate how much the bird could predate on the locusts. During the experiment duration of 32 days, a total of 1079 larval and 2083 fledglings were fed to the caged birds. The results showed that almost 100 percent of the larval and 97 percent of the fledglings were fed on during this duration (Table 3). The EP for the larvae was calculated to be 77, while for the fledglings it was 65 . The total EP

Table 3. Experimental predation of the black kite (Milvus migrans parasitus) bird.

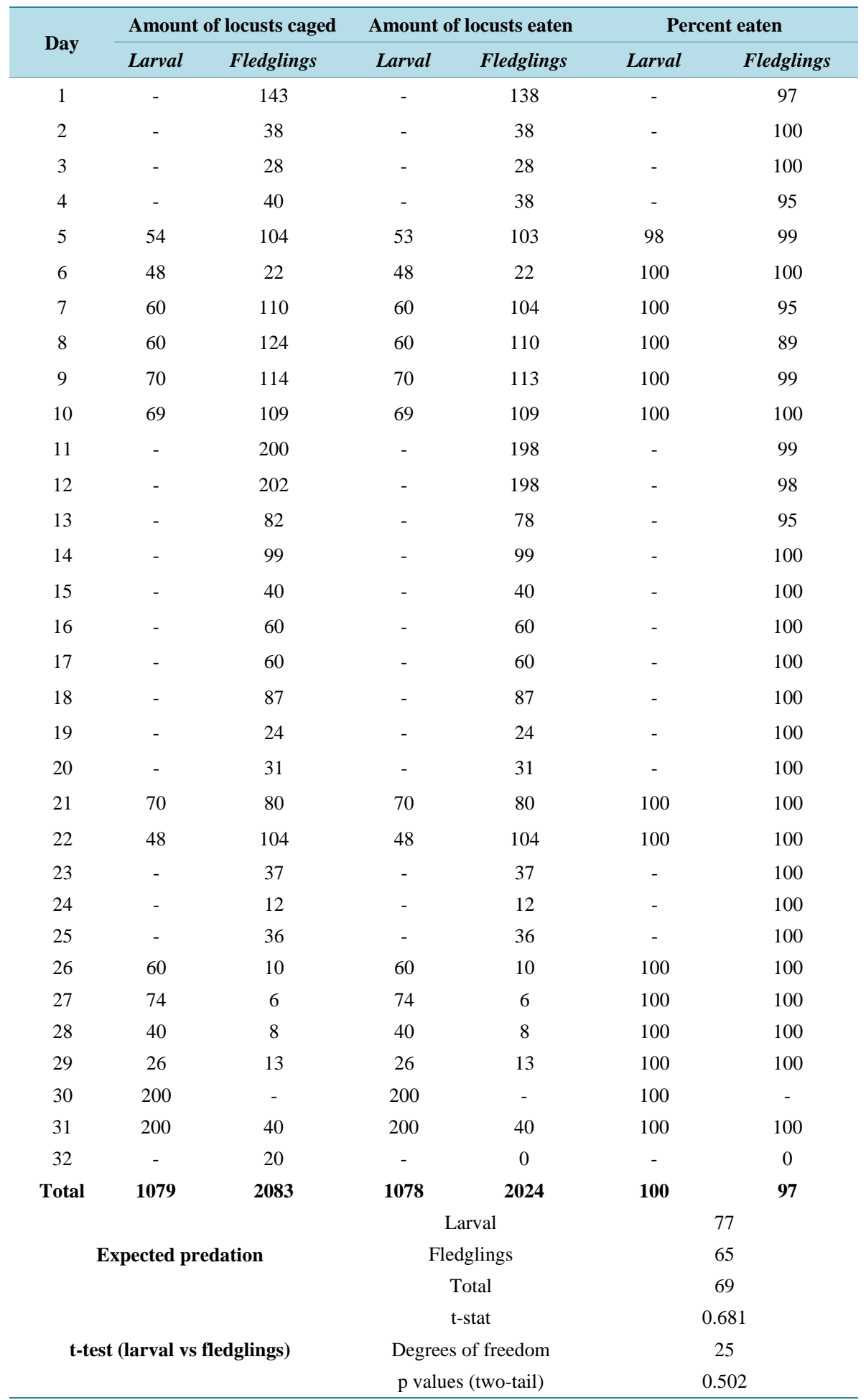


was calculated to be even higher than that of fledglings at 69 locusts per bird, and most importantly was higher than the OP calculations that had a total of 43 locusts per bird. This was not surprising because the birds in the cages had no limiting environmental factors in the cage that could limit the bird's ability to hunt locusts. The environmental factor identified in this study was mainly the vegetation type, but others could include terrain, weather conditions such as precipitation limiting flight and competition with other insectivores. The EP results also showed that there was no preference for larvae or fledglings in the cage and that the bird's fed on the different combinations equally (Table 3).

\section{Discussion}

Ecosystems are known for their roles in supporting their various members with resources for survival and other services that are crucial for individual organisms, but also their species as a whole. In the ecosystems, the food web is an interaction of organisms at different trophic levels that controls the performance of the general ecosystem, in terms of numbers. Two main approaches are central to the determination of the food web in an ecosystem and they include the top-down and bottom-up approaches (Hunter and Price, 1992 [19]; Polis et al., 1997 [20]). The top-down approach is a type of mechanism that is controlled by the organisms up the food web, which are the main consumers; while the bottom-up approach is the opposite of its counterpart as it is resource driven, which means it is controlled by organisms that are at lower levels in the food chain (Mantyla et al., 2011 [21]). These approaches have formed the basis for this study, where plants are the producers fed on by locusts that in turn are preyed on by insectivorous birds. However, locusts' swarms have been responsible for unsustainable consumption of plants, particularly crops in this case, to warrant the need for their predators in the ecosystem to control them. If an ecosystem is productive enough to facilitate the existence of vertebrate predators, the "ecosystem exploitation hypothesis" predicts that predators keep the population sizes of the notorious prey low, thus enabling plants to grow and reproduce (Oksanen and Oksanen, 2000) [22].

Observed predation (OP) of the Black Kite (Milvus migrans parasitus) bird was done by examining the bird's stomach contents to determine the number of locusts that were eaten. In performing this particular observation, this study predicted if the birds were able to enforce the ecosystem exploitation hypothesis in order to control gregarious phase of locusts. The results of the OP have shown the effect of vegetation on the ability of the Black Kite to feed on the locusts. Locust's reproduction involves laying of eggs in the soil and the larvae that don't have wings hop in vegetation that is close to the ground (Ambar, 2003 [23]; Massey et al., 2007 [24]). The Heteropogon contortus vegetation hosted a large number of locust larvae that were highly fed on by the birds. Similarly the wastelands, which are abandoned agriculture lands that were undergoing natural vegetation re-growth, had a large number of locust larvae. However, in areas with taller vegetation, the adults' locust were dominant type found in the Black Kite bird stomach, which supported the observation that vegetation was associated to the size of locust found. The type of vegetation plays a role in attracting the birds to feed on insects that feed on it (Jones and Sieving, 2006) [25]. It was normal to observe in our study that birds caught in savannah and partly dry forest had a high number of locusts in their stomachs, maybe because the birds were attracted to this area.

Care in interpreting the results of stomach contents in birds was considered in this study, specifically on the number of adults and hoppers. In terms of numbers, the adult locusts were found in fewer numbers because they are larger in size hence the birds had to capture more hoppers than the adult locusts. This led to the experimental predation to assess if the Black Kite preferred eating hoppers or the adult locusts. A total of 1079 larval and 2083 fledglings were fed to the caged birds. The results showed that almost 100 percent of the larval and 97 percent of the fledglings were fed on during this duration. The EP for the larvae was calculated to be 77 , while for the fledglings it was 65. Most avian species have opportunistic traits in their feeding habits, switching food types to take advantage of readily available food sources. For instance, during an insect outbreak in a Polish forest, predation of passerine nests declined, as predators switched to feeding on caterpillars (Tomialojc and Wesolowski, 1990) [26]. This indicates that the Black Kite bird generally feeds on the readily available locust that can easily be caught by the bird. Since the adult locusts are difficult to capture than the hoppers, then it would be no surprise that the fledglings were mostly captured in both experiments.

This study showed that the Black Kite birds can effectively control locust population in an outbreak when they are easy to predate on. Furthermore, the birds can be used as part of an IPM approach that can be used with other strategies. Despite the positive observation of this study, there is a need to assess the population of birds in locust infested areas to determine if the bird population is enough to predate on a locust outbreak and make an 
effective contribution to an integrated locust control approach. Such an assessment would correlate between the population of Black Kite and the role they can play in an IPM initiative. The role of parasites and predators, as a factor in the regulation of locust populations, has been thoroughly investigated and widely debated in the literature (Kirk et al., 1996 [16]; Szabo, 2005 [27]; Fildes et al., 2006 [28]; Whelan et al., 2008 [29]). The effects of predators and parasites are suggested to be modified by environmental conditions and by the stage of the outbreak (Wenny et al., 2011) [30]. Few natural enemies are associated with locust populations during the build-up phase, as parasites and predators depend on stable or declining populations (Lomer et al., 1999) [31].

\section{References}

[1] Tiffen, M. (2003) Transition in Sub-Saharan Africa: Agriculture, Urbanization and Income Growth. World Development, 31, 1343-1366. http://dx.doi.org/10.1016/S0305-750X(03)00088-3

[2] Hertel, T.W. and Rosch, S.D. (2010) Climate Change, Agriculture, and Poverty. Applied Economic Perspectives and Policy, 32, 355-385. http://dx.doi.org/10.1093/aepp/ppq016

[3] Lecoq, M., Andriamaroahina, T.R., Solofonaina, H. and Gay, P.E. (2011) Ecology and Population Dynamics of Solitary Red Locusts in Southern Madagascar. Journal of Orthoptera Research, 20, 141-158. http://dx.doi.org/10.1665/034.020.0202

[4] African Development Bank (2001) Preventive Locust Control, Madagascar: Appraisal Report. MAD/PAAC/2001/01. http://www.afdb.org/fileadmin/uploads/afdb/Documents/Project-and-Operations/Madagascar_-_Preventive_Locust_Co ntrol_-_Appraisal_Report.pdf

[5] Magor, J.I., Lecoq, M. and Hunter, D.M. (2008) Preventive Control and Desert Locust Plagues. Crop Protection, 27, 1527-1533. http://dx.doi.org/10.1016/j.cropro.2008.08.006

[6] Sánchez-Zapata, J.A., Donázar, J.A., Delgado, A., Forero, M.G., Ceballos, O. and Hiraldo, F. (2007) Desert Locust Outbreaks in the Sahel: Resource Competition, Predation and Ecological Effects of Pest Control. Journal of Applied Ecology, 44, 323-329. http://dx.doi.org/10.1111/j.1365-2664.2007.01279.x

[7] Lomer, C.J., Bateman, R.P., Johnson, D.L., Langewald, J. and Thomas, M. (2001) Biological Control of Locusts and Grasshoppers. Annual Review of Entomology, 46, 667-702. http://dx.doi.org/10.1146/annurev.ento.46.1.667

[8] Shelton, A.M. and Badenes-Perez, F.R. (2006) Concepts and Applications of Trap Cropping in Pest Management. Annual Review of Entomology, 51, 285-308. http://dx.doi.org/10.1146/annurev.ento.51.110104.150959

[9] Kar, T.K., Ghorai, A. and Jana, S. (2012) Dynamics of Pest and Its Predator Model with Disease in the Pest and Optimal Use of Pesticide. Journal of Theoretical Biology, 310, 187-198. http://dx.doi.org/10.1016/j.jtbi.2012.06.032

[10] Meehan, T.D., Lease, H.M. and Wolf, B.O. (2005) Negative Indirect Effects of an Avian Insectivore on the Fruit Set of an Insect-Pollinated Herb. Oikos, 109, 297-304. http://dx.doi.org/10.1111/j.0030-1299.2005.13578.x

[11] Meffe, G.K. (1998) The Potential Consequences of Pollinator Declines on the Conservation of Biodiversity and Stability of Food Crop Yields. Conservation Biology, 12, 8-17. http://dx.doi.org/10.1046/j.1523-1739.1998.97154.x

[12] Stiles, E.W. (2000) Animals as Seed Dispersers. In: Fenner, M., Ed., Seeds, the Ecology of Regeneration in Plant Communities, CABI Publishing, Wallingford, UK, 111-124. http://dx.doi.org/10.1079/9780851994321.0111

[13] Castro, J., Gómez, J.M., García, D., Zamora, R. and Hódar, J.A. (1999) Seed Predation and Dispersal in Relict Scots Pine Forests in Southern Spain. Plant Ecology, 145, 115-123. http://dx.doi.org/10.1023/A:1009865703906

[14] Howe, H.F. and Brown, J.S. (1999) Effects of Birds and Rodents on Synthetic Tallgrass Communities. Ecology, 80, 1776-1781. http://dx.doi.org/10.1890/0012-9658(1999)080[1776:EOBARO]2.0.CO;2

[15] Noordhuis, R., van der Molen, D.T. and van den Berg, M.S. (2002) Response of Herbivorous Water-Birds to the Return of Chara in Lake Veluwemeer, The Netherlands. Aquatic Botany, 72, 349-367. http://dx.doi.org/10.1016/S0304-3770(01)00210-8

[16] Kirk, D.A., Evenden, M.D. and Mineau, P. (1996) Past and Current Attempts to Evaluate the Role of Birds as Predators of Insect Pests in Temperate Agriculture. Current Ornithology, 13, 175-269. http://dx.doi.org/10.1007/978-1-4615-5881-1_5

[17] Cramp, S. and Simmons, K.E.L. (1980) The Birds of the Western Palearctic. Vol. II, Oxford University Press, Oxford.

[18] Fergusson-Lees, J. and Christie, D.A. (2001) Raptors of the World. Christopher Helm, London.

[19] Hunter, M.D. and Price, P.W. (1992) Playing Chutes and Ladders: Heterogeneity and the Relative Roles of Bottom-Up and Top-Down Forces in Natural Communities. Ecology, 73, 724-732

[20] Polis, G.A., Anderson, W.B. and Holt, R.D. (1997) Toward an Integration of Landscape and Food Web Ecology: The Dynamics of Spatially Subsided Food Webs. Annual Review of Ecology, Evolution, and Systematics, 28, 289-316. 
http://dx.doi.org/10.1146/annurev.ecolsys.28.1.289

[21] Mantyla, E., Klemola, T. and Laaksonen, T. (2011) Birds Help Plants: A Meta-Analysis of Top-Down Trophic Cascades Caused by Avian Predators. Oecologia, 165, 143-151. http://dx.doi.org/10.1007/s00442-010-1774-2

[22] Oksanen, L. and Oksanen, T. (2000) The Logic and Realism of the Hypothesis of Exploitation Ecosystems. American Naturalist, 155, 703-723. http://dx.doi.org/10.1086/303354

[23] Ambar, B. (2003) Meteorology and Desert Locust: Experience and Implementation of a Monitoring System. In: Zschau, J. Küppers, A., Eds., Early Warning Systems for Natural Disaster Reduction, Springer, Berlin Heidelberg, 619-623.

[24] Massey, F.P., Ennos, A.R. and Hartley, S.E. (2007) Herbivore Specific Induction of Silica-Based Plant Defences. Oecologia, 152, 677-683. http://dx.doi.org/10.1007/s00442-007-0703-5

[25] Jones, G.A. and Sieving, K.E. (2006) Intercropping Sunflower in Organic Vegetables to Augment Bird Predators of Arthropods. Agriculture, Ecosystems and Environment, 117, 171-177. http://dx.doi.org/10.1016/j.agee.2006.03.026

[26] Tomialojc, L. and Wesolowski, T. (1990) Bird Communities of the Primaeval Temperate Forest of Bialowieza, Poland. In: Keast, A., Ed, Biogeography and Ecology of Forest Bird Communities, SPB Academic Publishing, Hague, Netherlands.

[27] Szabo, J.K. (2005) Avian-Locust Interactions in Eastern Australia and the Exposure of Birds to Locust Control Pesticides. Doctoral Dissertation, Texas Tech University.

[28] Fildes, K., Astheimer, L.B., Story, P., Buttemer, W.A. and Hooper, M.J. (2006) Cholinesterase Response in Native Birds Exposed to Fenitrothion during Locust Control Operations in Eastern Australia. Environmental Toxicology and Chemistry, 25, 2964-2970. http://dx.doi.org/10.1897/05-585R.1

[29] Whelan, C.J., Wenny, D.G. and Marquis, R.J. (2008) Ecosystem Services Provided by Birds. Annals of the New York Academy of Sciences, 1134, 25-60. http://dx.doi.org/10.1196/annals.1439.003

[30] Wenny, D.G., Devault, T.L., Johnson, M.D., Kelly, D., Sekercioglu, C.H., Tomback, D.F. and Whelan, C.J. (2011) The Need to Quantify Ecosystem Services Provided by Birds. The Auk, 128, 1-14. http://dx.doi.org/10.1525/auk.2011.10248

[31] Lomer, C.J., Bateman, R.P., Dent, D., Groote, H.D., Douro-Kpindou, O.K., Kooyman, C. and Thomas, M. (1999) Development of Strategies for the Incorporation of Biological Pesticides into the Integrated Management of Locusts and Grasshoppers. Agricultural and Forest Entomology, 1, 71-88. http://dx.doi.org/10.1111/j.1461-9563.1999.tb00001.x 